\title{
Neurological soft signs correlation with symptom severity in borderline personality disorder
}

\author{
Aref A. Khoweiled, Yasmin Gaafar, Shirin M. El Makawi ${ }^{*}$, Reham M. Kamel and Doaa R. Ayoub
}

\begin{abstract}
Background: Borderline personality disorder (BPD) is a severe psychiatric disorder with multiple psychopathological domains; so studying the correlation of clinical or behavioral data with underlying structural and functional neurological findings in BPD is the focus of interest in recent years.

The aim of our study was to compare the presence of neurological soft signs (NSS) in patients with borderline personality disorder with their presence in normal controls, and to correlate the severity of different symptoms of BPD with the presence of NSS through a case-control study which was conducted on 30 patients and 30 matching controls recruited from Al Kasr Al Ainy Hospital, Cairo University, Egypt. All subjects were assessed by the Borderline Personality Questionnaire, the Barratt Impulsivity Scale-11, the Brief Non-Suicidal Self-Injury Assessment tool, and the Cambridge Neurological Inventory.

Results: The BPD group had significantly higher total NSS scores, primitive reflexes subscale score, and sensory integration subscale scores. There was also a positive correlation between NSS and overall severity of borderline symptoms.
\end{abstract}

Conclusions: The increased rates of NSS were associated with specific clinical symptoms in BPD including suicidality, self-harm, emptiness, and quasi-psychosis. Impulsivity was found to have the highest correlation with NSS.

Keywords: Borderline personality disorder, Neurological soft signs, Impulsivity, Suicidality, Self-harm

\section{Background}

Borderline personality disorder (BPD) is a severe and heterogeneous mental disturbance connoted by a pattern of identity diffusion, interpersonal disturbances, and chronic instability, with episodes of severe affective and impulsive discontrol [1].

This disorder is a leading contributor to the burden of disease in the community as it is associated with adverse long-term outcomes that include severe and continual functional disability [2], physical ill health [3], and premature mortality [4].

\footnotetext{
* Correspondence: shirinelmakawi@yahoo.com

Department of Psychiatry, Faculty of Medicine, Cairo University, Cairo 12311, Egypt
}

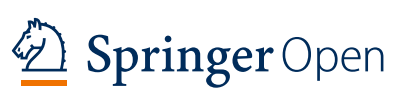

(ㄷ) The Author(s). 2021 Open Access This article is licensed under a Creative Commons Attribution 4.0 International License, which permits use, sharing, adaptation, distribution and reproduction in any medium or format, as long as you give appropriate credit to the original author(s) and the source, provide a link to the Creative Commons licence, and indicate if changes were made. The images or other third party material in this article are included in the article's Creative Commons licence, unless indicated otherwise in a credit line to the material. If material is not included in the article's Creative Commons licence and your intended use is not permitted by statutory regulation or exceeds the permitted use, you will need to obtain permission directly from the copyright holder. To view a copy of this licence, visit http://creativecommons.org/licenses/by/4.0/. on the structural and functional neurological manifestations of BPD; therefore, studying the correlation of clinical or behavioral data with the underlying neurological findings in BPD has been always an area of interest for researchers with the advances of knowledge [5-7].

While there was no specific focal neurological deficit identified in patients with BPD [8], there was an increased observation of mild neurological soft signs in this population (NSS) [9, 10]; in fact, De la Fuente et al. [9] in their study found that 13 of the soft neurological signs were significantly higher in borderline personality disorder patients than controls.

NSS indicate a nonspecific brain dysfunction related to a non-focal neurological impairment [11], and they are 
only evidenced by specific motor, sensory, or integrative testing; they are subdivided into three main domains: sensory integration, motor coordination, and primitive reflexes [12].

Neurological soft signs have been studied in several psychiatric populations, initially schizophrenia, afterwards obsessive compulsive disorder, bipolar disorder, and others, while they have been more recently studied in BPD; apart from diagnosis, patients with different diagnoses showed more NSS than healthy subjects, NSS were already present at the onset of the disease and showed a significant correlation with psychopathological measures [13-16]. In addition, later attempts to link NSS with common symptoms in BPD have shown, among others, that higher impulsivity was linked to higher NSS [17].

Therefore, we believed that studying NSS in BPD would extend our understanding of BPD and their underlying mechanisms.

The hypothesis of this research was that borderline personality disorder correlates with a significantly high prevalence of neurological soft signs and that neurological soft signs are related to the severity of psychopathology in patients with borderline personality disorder.

The aim of study at hand was to compare the presence of neurological soft signs in patients with borderline personality disorder with their presence in normal controls, and to correlate the severity of different symptoms of borderline personality disorder with the presence of neurological soft signs.

\section{Methods}

\section{Study characteristics}

This was a comparative, cross-sectional, case-control study. It was a convenient sample; participants were recruited from the Adult Outpatient Clinic of the Psychiatry and Addiction Prevention Hospital, Kasr Al Ainy Hospitals, Faculty of Medicine, Cairo University, Egypt.

The outpatient services are conducted daily from 8 to $1 \mathrm{pm}$. The department receives about 90 new patients per week covering the whole array of diagnoses; males are slightly more than females.

- Geriatric services

- Adolescent services

- Addiction services

- Emergency services

- General adult services

- Child services

\section{Sample selection}

Thirty adult females with BPD and 30 healthy adult females fulfilling the study inclusion and exclusion criteria were included. They were matched for gender, handedness, and were all educated. The patients were interviewed by the Structured Clinical Interview (SCID I and II) for DSM-IV-TR criteria to exclude comorbid mental disorders and diagnose BPD, respectively. The GHQ-12 by Daradkeh et al. (2001) [18] was administered to the controls to only exclude any current Axis I psychiatric diagnosis. SCID II was also done to the controls with the aim of excluding BPD. Controls with BPD traits not mounting to the cut-off to diagnose BPD were excluded from the study.

Inclusion criteria for patient group were as follows: age range 20-30 years, females, fulfilling DSM-IV TR diagnostic criteria of BPD, educated, and able to read and write to fill the self-rated psychometric tests. The controls were healthy adult volunteers from Kasr AlAiny Hospital who were matched for age, gender, handedness, and education.

Exclusion criteria were any Axis I mental disorders according to DSM-IV TR diagnostic criteria, patients who have past psychiatric history were not included as well as neurological or medical comorbidity such as diabetes mellitus, renal disease, multiple sclerosis, local brain lesions, epilepsy, and any psychotropic or substance intake in the 6 weeks prior to examination by history taking or positive results in the urine toxicology drug screen.

During the process of subjects' collection:

- Four patients were excluded for having a current or lifetime diagnosis of another Axis I psychiatric disorder, e.g., mood disorder and substance use disorder

- Three patients were excluded as they had epilepsy, one patient for having primary nocturnal enuresis, and another patient for history of excised brain tumor.

- Six control subjects were excluded for exhibiting several borderline traits, although not mounting to a diagnosis of BPD.

- One control subject was excluded for showing mirror movements syndrome and another for having diabetes mellitus.

\section{Data collection tools and procedure} Semi-structured psychiatric interview

Psychiatric assessment was done for collection of sociodemographic variables, medical and neurological history, and detailed clinical history with special emphasis on past psychiatric history, past substance intake, and history of the presenting symptoms.

\section{Structured Clinical Interview for DSM IV-TR Axis I Disorders} (SCID-I) (First et al. 2002) [19]

SCID-I is a structured diagnostic interview designed for use by mental health professionals. It assesses 33 of the 
more commonly occurring psychiatric disorders described in the fourth edition of the DSM-IV of the APA.

\section{Structured Clinical Interview for DSM-IV Axis II Disorders (SCID-II) (First et al. 1997) [20]}

SCID-II is a valid and reliable instrument. It was applied to participants to assess for BPD. It is a semi-structured interview of 140 items which provides an assessment of 35 DSM-IV Axis II personality disorders as well as depressive personality disorder, passive-aggressive personality disorder, and personality disorder not otherwise specified (NOS). Only the part for borderline personality disorder was applied to the participants.

\section{Borderline Personality Questionnaire (BPQ) by Poreh et al. (2006) [21] and the Arabic version by Goueli et al. (2016) \\ [22]}

The BPQ was developed for assessment of the borderline personality based on DSM-IV criteria. It is a self-report made up of 80 statements with dichotomous response format (true/false). It has a total of 9 subscales: impulsiveness, affective instability, abandonment, relationship, self-image, suicide/self-mutilation, emptiness, intense anger, and quasipsychotic states. It has been specifically accredited for use in the detection of BPD in young population [23].

Barratt Impulsivity Scale-11 by Patton et al. (2006) [24] andArabic version by Agoub et al. (2005) [25]

BIS-11 is the most commonly administrated self-report measure for the assessment of impulsivity in both research and clinical settings. It is a 30 -items self-report questionnaire with responses in a four-point Likert scale. It has good validity and reliability. Impulsiveness is composed of three subtraits: attentional impulsiveness defined as an inability to focus attention or concentrate ( 8 items), motor impulsiveness defined as acting without thinking (11 items), and non-planning impulsiveness defined as a lack of forethought (11 items).

Brief Non-Suicidal Self-Injury-Assessment Tool (BNSSI-AT) by Whitlock and Purington (2011) [26] and Arabic version by EI Bakry et al. (2018) [27]

An initial screening question for self-injurious behavior "Have you ever done any of the following with the purpose of intentionally hurting yourself?" is followed by a list of 19 NSSI behaviors. Participants were then asked a series of closed-ended questions that assessed general NSSI characteristics: age of onset and cessation, lifetime frequency, last time of self-injury, psychological functions (e.g., stress relief, self-punishment), motivations for initiating NSSI (e.g., self-anger), and body areas affected (e.g., arms, legs).
Beck Scale for Suicidal Ideation (BSSI) by Beck et al. (1979) [28]

BSSI is a clinician-rating scale and is presented in a semi-structured interview format. It is designed to quantify and assess suicidal intention. The scale was found to have a high internal consistency and moderately high correlation with clinical ratings of suicidal risk and selfadministrated measures of self-harm.

\section{Cambridge Neurological Inventory by Chen et al. (1995)}

[29]

The Cambridge Neurological Inventory was constructed for standardized neurological assessment of psychiatric patients. It is comprehensive, reliable, and easy to administer. Part 2 of the inventory was designed for soft sign examinations (primitive reflexes; repetitive movement; sensory integration). Soft signs that could be scored on both the left and right sides were treated as independent scores. Higher scores indicate more severe NSS.

\section{Data analysis}

Statistical analysis statistics were calculated by the Statistical Package for the Social Sciences (SPSS) (IBM, 2015) [30] version 20.15. Frequency (percent) and mean \pm SD were used to describe data. Comparisons and correlations were calculated using Mann-Whitney test and Spearman correlation test respectively. $P$ value $<0.05$ was considered significant.

\section{Ethical considerations}

The Ethical Committee of Psychiatry Department, Kasr Al Ainy, approved this research protocol.

An informed written consent was taken from all subjects participating in the study after discussing with them the aim of the study.

The following general principles were explained to all those who participated in this study:

- Participation in this study is totally free and voluntary.

- Participation in this study does not imply a direct benefit for the participant.

- The participant has the right to withdraw his consent for participation at any time and without any justification, and that this will not affect the quality of the medical services provided to him/her.

- The data obtained by the investigators could be used in scientific publication but the identity of the participant will be absolutely confidential.

\section{Results}

All patients were females, mean age was $23.633 \pm 3.16$ years, educated $(21 \%$ had college education $(n=7)$, 63.3\% had secondary education $(n=19)$, and $12 \%(n=$ 
4) had preparatory education); age and education were not statistically different between groups (mean age of the controls was $26.433 \pm 2.20$ years, $24 \%$ of the control group had college education, $35 \%$ had preparatory education, and the rest had secondary education). However, they showed statistically significant difference as regards their marital and occupational status $(p<0.001)$. The mean scores of all domains of the BPQ in the patient group were statistically significantly higher than those in the control group $(p<0.001)$. The mean scores of the patient group were statistically significantly higher than the control group in attention, motor, non-planning, and impulsivity $(p \leq 0.001)$. The mean scores of Beck Scale for Suicidal Ideation in the patients and controls showed that $66.7 \%$ of the patients $(n=20)$ had high suicidal intent and only $33.3 \%$ of them $(n=35)$ had medium suicidal intent while all controls had low suicidal intent.

According to Brief Non-Suicidal Self-Injury Assessment Tool (BNSSI-AT), ingestion of medications (73\%), cutting (53\%), and scratching or pinching (43\%) were the three most common methods. Fifty percent of the patients have done NSSI in the past month. "Self-hatred" was the most common cause/function of NSSI (73.3\%), followed by "coping with uncomfortable feelings" $(66.7 \%)$ as reported by the patients in this study. About half of the patients (46.5\%) found it very likely, that they would repeat NSSI in the future. None of them found it very unlikely to repeat the NSSI whereas $23.3 \%$ were unsure. Mean age at onset of self-harm has been shown to be 15.77 years \pm 6.02 . Almost $67 \%$ of the patients reported that "being angry at someone else" was their motive to inflict NSSI for the first time, followed by $63 \%$ who "were upset and decided to try." Neurologic soft signs were present in both groups; however, there was a statistically significant difference in the primitive reflexes, sensory integration subtests, and in the total score of the NSS ( $p 0.002,0.004$, and 0.005 , respectively) but not in the repetitive movements subtest (Table 1).

The correlations between the NSS scores and scores of the BPQ in the patient group were done using Spearman's correlation coefficient which showed a positive correlation between repetitive movements of NSS and impulsivity, suicide and self-harm, and quasi-psychosis subscales of the BPQ. Sensory integration of the NSS was also positively correlated with emptiness subscale

Table 1 Cambridge Neurological Inventory results for the NSS

\begin{tabular}{|c|c|c|c|c|c|}
\hline & \multicolumn{2}{|c|}{ Patients } & \multicolumn{2}{|c|}{ Controls } & \multirow[t]{2}{*}{$p$ value } \\
\hline & Mean & SD & Mean & SD & \\
\hline Primitive reflexes & 0.17 & 0.38 & 0 & 0 & 0.02 \\
\hline Repetitive movements & 7.67 & 3.2 & 6.07 & 2.53 & 0.07 \\
\hline Sensory integration & 3.93 & 2.29 & 2.27 & 1.87 & 0.004 \\
\hline Total score & 11.77 & 4.71 & 8.1 & 3.8 & 0.005 \\
\hline
\end{tabular}

and the total score of the BPQ. Finally, the total score of NSS was positively correlated with impulsivity, intense anger subscales 0.043 , and the total score of the BPQ (Table 2). There was a positive correlation between most of the domains of Barratt's Impulsivity Scale and the 3 subtests of NSS (Table 3). Some of the relations were highly statistically significant, namely that between attentional impulsivity and repetitive movements or the total score of NSS, as well as that between the total attentional impulsivity and the same items of NSS, and also between motor impulsivity and the total NSS score.

There was a positive correlation between NSS scores and suicide in the patient group (Table 4). This difference, however, was not statistically significant, but was strongest in relation to the Sensory Integration Subtest of NSS.

\section{Discussion}

In a review by Turner et al. (2017) [31] studying impulsivity in cluster B personality, heightened impulsivity was found to be a core personality trait in BPD and ASPD that, however, different components of experimentally measured impulse control are affected in BPD and ASPD, and impulsivity occurring in negative emotional states or increased distress seems to be specific for BPD.

The statistically significant higher scores of the patients than those of the controls on all aspects of impulsivity (attentional, motor, and non-planning), as measured by BIS-11, denoted that patients had a greater tendency to accept the immediately available lesser reward rather than waiting longer for a greater reward. This was consistent with Zamalloa et al. (2016) [32] where they showed that there were differences in the overall impulsivity with higher levels in patients with BPD.

Yet, regarding the subscales of the BIS, there were significant differences in motor impulsiveness and in nonplanning impulsiveness only with higher results in the BPD group

Barker et al. (2015) [33], on the other hand, showed that while motor impulsivity was not significantly different in participants with BPD compared with controls, choice or reward-related impulsivity was significantly affected in those with BPD.

Suicidality was an evident feature in the BPD patients in this study, where $67 \%$ of them had high suicidal intent and the remaining $33 \%$ of the patients had medium suicidal intent. This was opposed to all controls, which had all low suicidal intent. This might point to the severity of the BPD features, especially being females with intense underlying psychopathology. This was consistent, among many others, with the study conducted by Zhang et al. (2017) [34] which also discovered that suicidal ideation was prevalent, intense, and statistically higher in BPD patients than those in control group. 
Table 2 Correlation between NSS results and the Borderline Personality Questionnaire

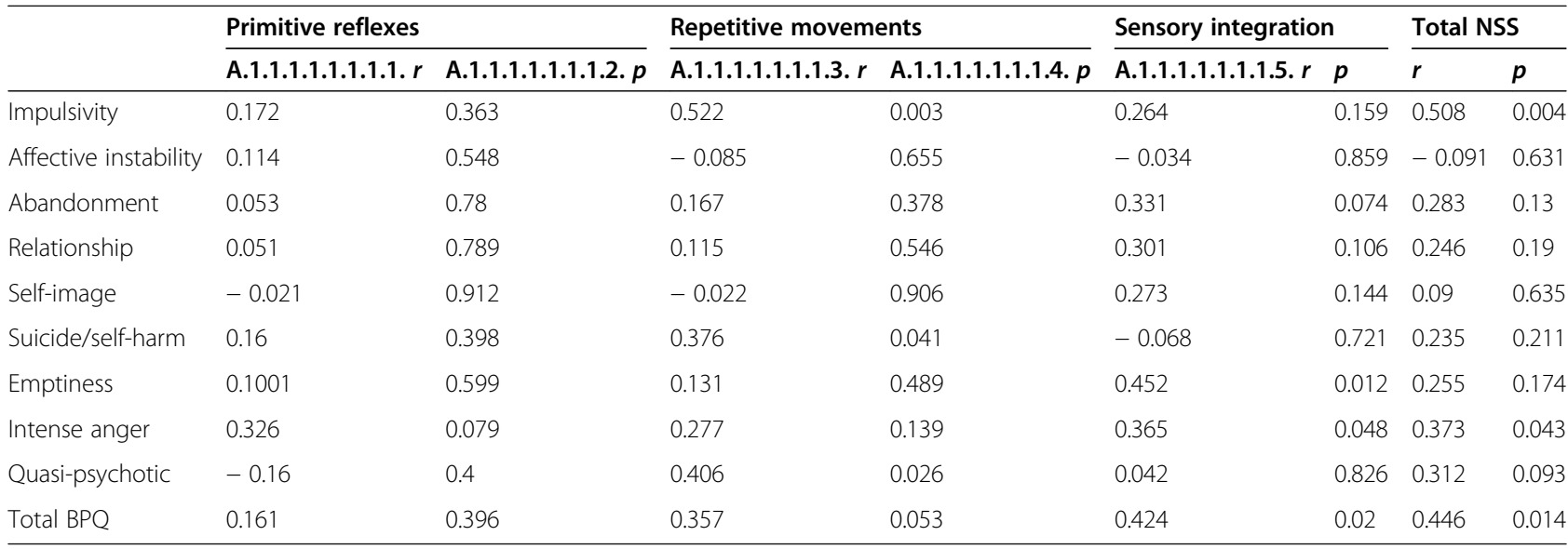

$p \leq 0.05$ is significant

$r$ correlation coefficient

Results of this study indicated that patients with BPD compared to the control group show mild neurological impairments particularly in the sensory integration and primitive reflex domains, as well as the total NSS score. There was no significant difference between the two groups regarding the subscale for repetitive movements. Our research results furthermore showed a significant difference between both groups regarding 4 soft signs in particular, namely palmo-mental reflex, rhythm-tapping, finger-agnosia on the right side and right-sided mirror movements. Moreover, it showed that BPD patients had more right-sided soft signs compared to controls; however, there was no significant difference between the amounts of left- and right-sided NSS in the patients, implying absence of laterality. These results were consistent with Gardner et al. (1987) [35], Zhang et al. (2015) [5], where the authors speculated that NSS abnormalities may be associated with the development of BPD.

NSS in neuropsychiatric disorders have been hypothesized to occur through two possible ways: either those signs persist beyond the expected age and may constitute evidence of a more vulnerable nervous system or, instead, that NSS can appear de novo and may represent some loss of inhibition similar to that observed in the (archaic) primitive reflexes of dementia [36]. Archaic means primitive reflexes as illustrated in the mentioned reference.

In this context, data from neuro-imaging results suggest that NSS may represent abnormalities in neuronal maturity and neural integration [37]. Exact localization of NSS-related deficits has been a subject for debate, while some studies claim that NSS are associated with structural and functional changes in cortical and

Table 3 Correlation between NSS results and Barratt Impulsivity Scale-11

\begin{tabular}{|c|c|c|c|c|c|c|c|c|}
\hline & \multicolumn{2}{|l|}{ Primitive reflexes } & \multicolumn{2}{|c|}{ Repetitive movements } & \multicolumn{2}{|c|}{ Sensory integration } & \multicolumn{2}{|c|}{ Total NSS } \\
\hline & $\begin{array}{l}\text { A.1.1.1.1.1.1.1.6. } \\
r\end{array}$ & $\begin{array}{l}\text { A.1.1.1.1.1.1.1.7. } \\
p\end{array}$ & $\begin{array}{l}\text { A.1.1.1.1.1.1.1.8. } \\
r\end{array}$ & $\begin{array}{l}\text { A.1.1.1.1.1.1.1.9. } \\
p\end{array}$ & $\begin{array}{l}\text { A.1.1.1.1.1.1.1.10. } \\
r\end{array}$ & $p$ & $r$ & $p$ \\
\hline Attentional impulsiveness & 0.125 & 0.511 & 0.608 & $<0.001$ & 0.404 & 0.027 & 0.582 & $\begin{array}{l}< \\
0.001\end{array}$ \\
\hline Cognitive instability & -0.189 & 0.317 & 0.273 & 0.145 & -0.047 & 0.805 & 0.231 & 0.22 \\
\hline $\begin{array}{l}\text { Total attentional } \\
\text { impulsiveness }\end{array}$ & 0.057 & 0.765 & 0.656 & $<0.001$ & 0.366 & 0.047 & 0.636 & $\begin{array}{l}< \\
0.001\end{array}$ \\
\hline Motor impulsiveness & 0.489 & 0.006 & 0.502 & 0.005 & 0.313 & 0.092 & 0.589 & $\begin{array}{l}< \\
0.001\end{array}$ \\
\hline Perseverance & 0.172 & 0.363 & 0.16 & 0.4 & 0.433 & 0.017 & 0.27 & 0.149 \\
\hline Total motor impulsiveness & 0.42 & 0.021 & 0.42 & 0.021 & 0.426 & 0.019 & 0.546 & 0.002 \\
\hline Self-control & 0.385 & 0.036 & 0.412 & 0.024 & 0.535 & 0.002 & 0.527 & 0.003 \\
\hline Cognitive complexity & 0.338 & 0.068 & 0.071 & 0.71 & 0.327 & 0.077 & 0.197 & 0.298 \\
\hline $\begin{array}{l}\text { Total non-planning } \\
\text { impulsiveness }\end{array}$ & 0.415 & 0.023 & 0.271 & 0.148 & 0.477 & 0.008 & 0.418 & 0.022 \\
\hline
\end{tabular}

$p \leq 0.05$ is significant

$r$ correlation coefficient 
Table 4 Correlation between NSS results and Beck Suicidal Ideation Scale

\begin{tabular}{lll}
\hline & \multicolumn{2}{l}{ Beck's suicidal ideation } \\
\cline { 2 - 3 } & A.1.1.1.1.1.1.1.11. $\boldsymbol{~ A . 1 . 1 . 1 . 1 . 1 . 1 . 1 . 1 2 . ~} \boldsymbol{P}$ \\
\hline Primitive reflexes & 0.243 & 0.195 \\
Repetitive movements & 0.127 & 0.503 \\
Sensory integration & 0.33 & 0.075 \\
Total NSS & 0.238 & 0.206 \\
\hline
\end{tabular}

$p \leq 0.05$ is significant

$r$ correlation coefficient

subcortical brain networks and connections responsible for the integration of motor and sensory processes such as the basal ganglia, prefrontal, and temporal cortices, as well as the cerebellum as illustrated by Zhao et al. (2014) [38]; others saw the default mode network as an important cornerstone in the genesis of NSS [39] or that neural mechanisms underlying NSS rely on cortically mediated motor control and planning to a higher degree than on functions subserved by subcortical structures [40].

NSS are additionally associated with a wealth of cognitive deficits ranging from attention/psychomotor speed and executive dysfunctions to complex neuropsychological abilities, such as logical memory, autobiographic episodic memory, and theory of mind [38, 41]. Reflections of these dysfunctions in the pathology of BPD are quite evident, particularly in the areas of impulsivity and theory of mind. As the significant frequency of sensory integration soft signs may imply general cognitive impairment and BPD is characterized by impulsivity and various cognitive impairments [42], the results of this study indicate that BP symptoms and NSS may share the same neural substrates.

In this study, we found significant correlations between NSS and collective severity of borderline symptoms (as represented by the total BPQ score), particularly impulsivity, suicide and self-harm, intense anger, sense of emptiness, and quasi-psychosis. Positive correlation between NSS and impulsivity was also evident within the controls. To our knowledge, this study is the first to show a positive correlation between NSS in borderline patients and suicide and self-harm, intense anger, emptiness, and quasi-psychosis. We revealed a clear positive correlation between all domains of impulsivity and the three subtests of NSS as well as the total score of NSS. This was consistent with findings of Arbabi et al. (2016) [35], who eventually concluded, that the total score of NSS in BPD was significantly higher than controls.

They also showed that although anxiety and depression as reported by the respective scales correlated with NSS, the impulsivity score was the best significant predictor of NSS in BPD. Although there was correlation of the results obtained from the Beck Suicidal Ideation scale with NSS results yet it was not statistically significant; the subscale for suicide and self-harm showed a positive correlation with the repetitive movement subscale of the Cambridge Neurological Inventory for NSS assessment. Although there is no available literature linking severity of suicidality in BPD to NSS score, yet this link has previously been made in depressive patients with history of childhood maltreatment, where Zhao et al. (2015) [43] discovered that severity of suicidality correlated positively with NSS score.

Moreover, our study revealed a positive correlation between the score of Beck suicidal ideation and abandonment, relational problems, and the total score of the BPQ. This was in line with findings of Pérez et al. (2014) [44], who found that across BPD patients with suicidal attempts and NSSI, and those with only NSSI, and those with neither of the two, the clinician perceived severity was significantly higher among those who had suicidal attempts and NSSI.

As far as the researchers know, this work is the earliest to investigate the association between suicidality, abandonment, and relationship instability in BPD. Theoretically speaking that higher suicidality affects relationships stability, and in turn a disturbed relationship pattern and fear of abandonment could lead to higher suicidality. Similarly, Brodsky et al. (2006) [45] in their study comparing suicide attempters with MDD comorbid with BPD with attempters with only MDD found that the former were more likely to have interpersonal triggers, such as conflict with partner or parent, for their suicide attempts. All of the above support the clinical observation that borderline patients react destructively when faced with interpersonal conflicts.

Although Links et al. (2007) [46] found a significant correlation between affective instability and suicidality, this could not be proven in our study. Furthermore, we showed a positive correlation between severity of suicidality and the total non-planning impulsiveness. This is consistent with findings of Andrews et al. (2019) [47], who found impulsivity to be predictive of suicide attempt frequency. The association of suicidality with non-planning impulsivity in the context of BPD was not previously shown, yet Malloy-Diniz et al. (2011) [48] proved that euthymic bipolar patients with history of a suicide attempt exhibited greater non-planning impulsiveness than those without and healthy controls. In our study, we also showed a negative correlation between the total number of NSSI and perseverance (i.e., the ability to remain focused or to complete a difficult or boring task) and a positive correlation between the number of NSSI and cognitive instability subscale of Barratt's Impulsivity Scale. This was consistent with previous findings of a large meta-analysis conducted by Hamza et al. 
(2015) [49] that showed that individuals who engaged in NSSI reported less perseverance than individuals who did not engage in NSSI, suggesting lower levels of distress tolerance, relative to individuals who do not engage in NSSI. In the context of intense negative affect, they engage in coping behaviors to provide immediate relief from distress, with disregard for long-term consequences. Later, Hamza and Willoughby (2019) [50] further revealed that impulsivity may not only lead to NSSI, but that frequent engagement in NSSI may also undermine regulatory skill development and lead to greater impulsivity over time during the emerging adult years.

\section{Strengths and limitations of the research}

Limitations of the research include the relatively small sample size that could limit generalization of the findings; this size, however, has been agreed on to be able to fulfill the high number of exclusion criteria. Including imaging techniques in future studies would help to correlate NSS with brain structural abnormalities in BPD. The study subjects were all females; studying NSS on populations with mixed gender would provide a more comprehensive view about NSS in this disorder.

To the knowledge of the investigators, this work is the earliest to show a positive correlation between NSS in borderline patients and suicide, self-harm, intense anger, emptiness, and quasi-psychosis. Also, it is the first to address the correlation between suicidality, abandonment, and relationship instability in BPD patients.

\section{Conclusions}

This work revealed a higher rate of NSS in BPD patients confirming the presence of non-localized CNS dysfunction in patients with BPD.

Positive correlations between NSS and borderline symptoms, particularly impulsivity, suicide and selfharm, intense anger, sense of emptiness, and quasipsychosis.

Impulsivity as a domain was found to have the highest correlation with NSS.

\section{Abbreviations}

DSM-IV: Diagnostic and Statistical Manual of Mental Disorders 4th Edition; NSS: Neurological soft signs; SCID I: Structured Clinical Interview for DSM-IV; BPD: Borderline personality disorder; NSSI: Non-suicidal self injury; BPQ: Borderline Personality Questionnaire

\section{Acknowledgments}

Special thanks for Assistant Professor Mohammed Abd elFattah Khalil, Faculty of Medicine, Cairo University, for conducting the statistical analysis of the study.

\section{Authors' contributions}

All authors had made a substantial contribution to the design of work, data collection and interpretation, writing the manuscript, revising it, and approving the final version.

Y.G. made the main effort in patient data collection. R.K, S M.E, and D.R A made the major contribution in analyzing the results, reviewing current literature, and writing the manuscript. All authors read and approved the final manuscript.

Funding

The research was totally funded by the researchers.

\section{Availability of data and materials}

The data used and analyzed during the current study are available from the corresponding author on reasonable request.

\section{Ethics approval and consent to participate}

Approval of the ethical committee in Kasr Al-Ainy Psychiatry and Addiction Prevention Hospital was obtained before the beginning of the study. At the time of conducting this study, reference number was not applicable as the ethical approval was only a necessity at the departmental level without any other prerequisites from the university.

All participants were interviewed before participation to explain to them the procedure in details. A written informed consent was signed by each participant before the beginning of the study.

\section{Consent for publication}

Not applicable

\section{Competing interests}

On behalf of all authors, the corresponding author states that there is no conflict of interest, and that the study received no fund and was totally funded by the researches.

Received: 7 November 2020 Accepted: 4 December 2020 Published online: 04 January 2021

\section{References}

1. American Psychiatric Association (2013) Diagnostic and statistical manual of mental disorders, 5th edn. Author, Washington, DC. https://doi.org/10.1176/ appi.books.9780890425596

2. Gunderson JG, Stout RL, McGlashan TH, Shea (2011) Ten-year course of borderline personality disorder: psychopathology and function from the Collaborative Longitudinal Personality Disorders study. Archives General Psychiatry 68(8):827-837. https://doi.org/10.1001/archgenpsychiatry.2011.37

3. El-Gabalawy R, Katz LY, Sareen J (2010) Comorbidity and associated severity of borderline personality disorder and physical health conditions in a nationally representative sample. Psychosomatic Med 72(7):641-647. https:// doi.org/10.1097/PSY.0b013e3181e10c7b

4. Fok M, Hayes R, Chang C-K, Stewart R, Callard FJ, Moran P (2012) Life expectancy at birth and allcause mortality among people with personality disorder. J Psychosomatic Res 73:104-107. https://doi.org/10.1016/j. jpsychores.2012.05.001

5. Zhang J, Cai L, Zhu X, Yi J (2015) Neurological soft signs in adolescents with borderline personality traits. Int J Psychiatry Clin Practice 19(1):40-44. https://doi.org/10.3109/13651501.2014.981544

6. Laddis A (2015) The pathogenesis and treatment of emotion dysregulation in borderline personality disorder. Sci World J. https://doi.org/10.1155/2015/ 179276

7. Davies G, Hayward M, Evans S, Mason O (2020) A systematic review of structural MRI investigations within borderline personality disorder: Identification of key psychological variables of interest going forward. Psychiatry Res 286:112864

8. Burgess JW (1990) Cognitive Information Processing in Borderline Personality Disorder: A Neuropsychiatric Hypothesis. Jefferson Journal of Psychiatry 8(2):Article 7. https://doi.org/10.29046/JJP.008.2.004

9. De la Fuente JM, Bobes J, Vizuete C, Bascaran M-T (2006) Neurologic soft signs in borderline personality disorder. J Clin Psychiatry 67(4):541. https:// doi.org/10.4088/JCP.v67n0404

10. Arbabi M, Paast N, Karim HR, Faghfori S, Memari AH (2016) Mild neurological impairment may indicate a psychomotor endophenotype in patients with borderline personality disorder. Psychiatry Res 245:22-26. https://doi.org/10.1016/j.copsyc.2017.09.002

11. Buchanan RW, Heinrichs DW (1989) The Neurological Evaluation Scale (NES): A structured instrument for the assessment of neurological signs in schizophrenia. Psychiatry Research 27(3):335-350 https://doi.org/10.1016/ 0165-1781(89)90148-0 
12. Neelam, K., Garg, D. and Marshall, M. (2011). A systematic review and metaanalysis of neurological soft signs in relatives of people with schizophrenia. BMC Psychiatry 11, 139-146. /doi.org/10.1186/1471-244X-11-139

13. Negash A, Kebede D, Alem A, Melaku Z, Deyessaa N, Shibirea T, Fekadu A, Fekadu D, Jacobsson L, Kullgren G (2004) Neurological soft signs in bipolar I disorder patients. J Affective Disorders 80:221-230. https://doi.org/10.1016/ S01650327(03)00116-2

14. Dimitri-Valente, G., Rigucci, S., Manfredi, G., Girardi, P., Ferracuti, S. Neurological soft signs: significato e rilevanza nel corso della patologia psichiatrica. Uno screening obiettivo veloce per psicosi? [Neurological soft signs: meaning and relevance along the course of psychiatric illness. An objective and rapid screening for psychosis?]. Riv Psichiatr. 2012; 47(6):465478. Italian. doi: https://doi.org/10.1708/1178.13053. PMID: 23160107.

15. Fathy $H$, Khalil MA (2014) Neurological soft signs with respect to type of symptoms in patients with schizophrenia. Egyptian J Psychiatry 35(3):167

16. Tapancı Z, Yıldıım A, Boysan M (2018) Neurological soft signs, dissociation and alexithymia in patients with obsessive-compulsive disorder (OCD) and healthy subjects. Psychiatry Research 260:90-97

17. Kulacaoglu F, Solmaz M, Belli H, Ardic FC, Akin E, Kose S (2017) The relationship between impulsivity and attention-deficit/hyperactivity symptoms in female patients with borderline personality disorder. Psychiatry Clin Psychopharmacol 27(3):249-255

18. Daradkeh TK, Ghubash R, El-Rufaie OE (2001) Reliability, validity, and factor structure of the Arabic version of the 12-item General Health Questionnaire. Psychological Reports 89(1):85-94. https://doi.org/10.2466/pr0.2001.89.1.85

19. First, M.B., Spitzer, R. L., Gibbon, M. \& Williams, J. B. (2002). Structured clinical interview for DSM-IV-TR axis I disorders, research version, patient edition. SCID-I/P.

20. First MB, Gibbon M, Spitzer RL et al (1997) Structured clinical interview for DSMIV axis II personality disorders, (SCID-II). American Psychiatric Press, Washington, DC

21. Poreh AM, Rawlings D, Claridge G, Freeman JL, Faulkner C, Shelton C (2006) The BPQ: a scale for the assessment of borderline personality based on DSM-IV criteria. Journal of personality disorders 20(3):247-260. https://doi. org/10.1521/pedi.2006.20.3.247

22. Goueli, T., Nasreldin, M. \& Farouk, M. (2016). The Borderline Personality Questionnaire (BPQ) Arabic version. In: Farouk M. 2016. Social Cognition in adolescent females with borderline personality traits. Unpublished thesis submitted in partial fulfillment of master degree in psychiatry. Faculty of Medicine, Cairo University.

23. Chanen AM, Velakoulis D, Carison K (2008) Orbitofrontal, amygdala and hippocampal volumes in teenagers with first-presentation borderline personality disorder. Psychiatry Research: Neuroimaging 163(2):116-125. https://doi.org/10.1016/j.pscychresns.2007.08.007

24. Patton, J.H., Stanford, M.S., \& Barratt, E.S. (1995). Factor structure of the Barratt Impulsiveness Scale. J Clin Psychol, 51(6), 768-774. doi: 10.1002/10974679(199511)51:6<768::aid-jclp2270510607>3.0.co;2-1

25. Agoub G (2005) Assessment of impulsivity among patients with schizophrenia. Arab J Psychiatry 8:149-150

26. Whitlock J, Purington A (2011) Validity and reliability of the non-suicidal selfinjury assessment tool (NSSI-AT): Why use the NSSI-AT. In Poster presented at: 6th Annual Meeting of the International Society for the Study of Self-Injury

27. El Bakry, A.A, Ayoub, D.R. \& Marzouk, H.A. (2018). The Brief Non-Suicidal Selfinjury Assessment Tool (BNSSI-AT) Arabic version. In: Mansour, N. K. 2018. Attachment to parents in adolescent patients with non-suicidal selfinjurious behavior. Unpublished thesis submitted in partial fulfillment of master degree in psychiatry. Faculty of Medicine, Cairo University.

28. Beck AT, Kovacs M, Weissman A (1979) Assessment of suicidal intention: the Scale for Suicide Ideation. J Consulting Clin Psychol 47(2):343. https://doi. org/10.1037//0022-006x.47.2.343

29. Chen EY, Shapleske J, Luque R (1995) The Cambridge Neurological Inventory: A clinical instrument for assessment of soft neurological signs in psychiatric patients. Psychiatry Res 56:183-204. https:/doi.org/10.1016/0165-1781(95)02535-2

30. IBM Corp. Released (2015) IBM SPSS Statistics for Windows, Version 23.0. IBM Corp, Armonk

31. Turner D, Sebastian A, Tüscher O (2017) Impulsivity and cluster B personality disorders. Current Psychiatry Reports 19(3):15. https://doi.org/10.1007/ s11920-017-0768-8

32. Zamalloa I, Iraurgi I, Maruottolo C et al (2016) Impulsivity and executive function in borderline personality disorder. Actas Espanolas De Psiquiatria. 44:113-121
33. Barker V, Romaniuk L, Cardinal RN, Pope M (2015) Impulsivity in borderline personality disorder. Psychol Med 45(9):1955-1964. https://doi.org/10.1017/ S0033291714003079

34. Zhang J, Yang F, Wang X, Tong J (2017) Suicidal ideation and its risk factors in borderline personality disorder. Chinese J Behavioral Med Brain Sci 26(5): 426-430. https://doi.org/10.1186/1471-2458-12-524

35. Gardner DL, Lucas PB, Cowdry RW (1987) Soft sign neurological abnormalities in borderline personality disorder and normal control subjects. J Nerv Ment Dis 175(3):177-180. https://doi.org/10.1097/00005053198703000-00009

36. Martin I, Lauterbach M, Slade P, Luís H, DeRouen T, Martin M, Caldas A, Leitão J, Rosenbaum G, Townes B (2008) A longitudinal study of neurological soft signs from late childhood into early adulthood. Developmental Med Child Neurol 50(8):602-607 https://doi.org/10.1111/j. 1469-8749.2008.03043.x

37. Gay O, Plaze M, Oppenheim C et al (2013) Cortex morphology in firstepisode psychosis patients with neurological soft signs. Schizophrenia Bulletin 39(4):820-829. https://doi.org/10.1093/schbul/sbs083

38. Zhao Q, Li Z, Huang J, Yan C, Dazzan P, Pantelis C, Cheung EFC, Lui SSY, Chan RCK (2014) Neurological soft signs are not "soft" in brain structure and functional networks: evidence from ALE meta-analysis. Schizophrenia Bulletin 40(3):626-641. https://doi.org/10.1093/schbul/sbt063

39. Galindo L, Bergé D, Murray GK, Mané A, Bulbena A, Peréz V, Vilarroya O (2018) Default Mode network aberrant connectivity associated with neurological soft signs in schizophrenia Patients and Unaffected relatives. Frontiers Psychiatry 8:298. https://doi.org/10.3389/fpsyt.2017.00298

40. Thomann PA, Hirjak D, Kubera KM, Stieltjes B, Maier-Hein KM, Thomann PA (2015) Neural network activity and neurological soft signs in healthy adults. Behavioural Brain Res 278:514-519. https://doi.org/10.1016/j.bbr.2014.10.044

41. Herold CJ, Duval CZ, Lässer MM, Schröder J (2019) Neurological soft signs (NSS) and cognitive impairment in chronic schizophrenia. Schizophrenia Research: Cognition 16:17-24. https://doi.org/10.1016/j.scog.2018.12.002

42. Judd PH (2005) Neurocognitive impairment as a moderator in the development of borderline personality disorder. Development Psychopathol 17(4):1173-1196. https://doi.org/10.1017/s0954579405050558

43. Zhao H, Guo W, Niu W, Zhong A, Zhou X (2015) Brain area-related neurological soft signs in depressive patients with different types of childhood maltreatment. Asia-Pacific Psychiatry 7(3):286-291. https://doi. org/10.1111/appy.12172

44. Pérez S, Marco JH, García-Alandete J (2014) Comparison of clinical and demographic characteristics among borderline personality disorder patients with and without suicidal attempts and non-suicidal self-injury behaviors. Psychiatry Research 220(3):935-940. https://doi.org/10.1016/j.psychres.2014.09.001

45. Brodsky BS, Groves SA, Oquendo MA, Mann JJ (2006) Interpersonal Precipitants and Suicide Attempts in Borderline Personality Disorder. Suicide and Life-Threatening Behavior 36(3):313-322. https://doi.org/10.1521/suli. 2006.36.3.313

46. Links PS, Eynan R, Heisel MJ, Barr A, Korzekwa M, McMain S, Ball JS (2007) Affective instability and suicidal ideation and behavior in patients with borderline personality disorder. J Personality Disorders 21(1):72-86. https:// doi.org/10.1037/a0035619

47. Andrewes HE, Hulbert C, Cotton SM, Betts J, Ghanen AM (2019) Relationships between the frequency and severity of non-suicidal self-injury and suicide attempts in youth with borderline personality disorder. Early Intervention Psychiatry 13(2):194-201. https://doi.org/10.1111/eip.12461

48. Malloy-Diniz LF, Neves FS, de Moraes PHP, Romano-Silva MA, Krebs MO, Corrêa H (2011) The 5-HTTLPR polymorphism, impulsivity and suicide behavior in euthymic bipolar patients. J Affective Disorders 133(1-2):221226. https://doi.org/10.1016/j.jad.2011.03.051

49. Hamza CA, Willoughby T, Heffer T (2015) Impulsivity and nonsuicidal selfinjury: A review and meta-analysis. Clin Psychol Review 38:13-24. https://doi. org/10.1016/j.cpr.2015.02.010

50. Hamza CA, Willoughby T (2019) Impulsivity and nonsuicidal self-injury: A longitudinal examination among emerging adults. J Adolescence 75:37-46. https://doi.org/10.1371/journal.pone.0059955

\section{Publisher's Note}

Springer Nature remains neutral with regard to jurisdictional claims in published maps and institutional affiliations. 